\title{
GRAMSCI, AMERICANISMO E FORDISMO E A EDUCAÇÃO DO CORPO
}

\author{
Marcelo Paula Melo \\ Instituto Superior de Educação- FAETEC, Três Rios, Rio de Janeiro, Brasil
}

\begin{abstract}
Resumo
Este estudo trata de relevantes considerações feitas por Antonio Gramsci em Cadernos do cárcere, sobretudo no caderno 22 (Americanismo e fordismo), acerca de questões sobre o papel do corpo nas mudanças na sociedade capitalista nas décadas iniciais do século XX, embora o autor não tenha teorizado sobre algum aspecto específico do campo da Educação Física. Considerando que as bases de funcionamento daquela sociedade espraiaram-se por quase todo o globo, é de suma importância para o conjunto dos educadores a compreensão de como o capital não se descuidou de uma pedagogia do corpo, que incluía, mas nelas não se esgotava, as práticas corporais por meio do esporte e da disciplina curricular Educação Física.

Palavras-chave: Gramsci. Americanismo e Fordismo. Educação do corpo. Dominação.
\end{abstract}

\section{Primeiros passos}

O modo de produção social da existência é um conceito que pretende indicar um projeto societário que não se esgote unicamente na dinâmica produtiva de bens necessários à reprodução social dos seres humanos. Tal conceito busca apreender e indicar como as relações sociais travadas pelos seres humanos nas múltiplas esferas de sociabilidade são influenciadas pelas relações sociais empreendidas entre os seres humanos - e também entre eles e a natureza - no enfrentamento de suas múltiplas necessidades. Ao considerar que a partir do século XIX grande parte da população mundial passou a obter sua existência sob a influência de relações sociais capitalistas, é importante ter em mente como tal projeto não se cristaliza, demandando constantes mudanças em sua dinâmica de funcionamento.

É possível afirmar que desde as décadas iniciais do século XX o capitalismo passa por mais uma dessas intensas transformações em sua dinâmica de funcionamento. $\mathrm{O}$ novo modo de funcionamento das unidades produtivas nas grandes empresas, no que tange à organização do trabalho, ficou conhecido como taylorismo/fordismo, com base no direto envolvimento do engenheiro estadunidense Frederick Taylor e 
do empresário, também estadunidense, Henry Ford. Seus nomes passaram a ser associados a todo um modo de conceber a divisão sociotécnica do trabalho nas empresas, bem como a uma nova face do tipo de sociabilidade que vai além do espaço da produção fabril, atingindo outros ramos da vida regida pelas relações sociais capitalistas. Dentre essas alterações demandadas pela generalização da indústria nascente, havia a necessidade de uma nova relação do trabalhador - aqui tomado como vendedor de força de trabalho a um possuidor de meios de produção dos mais variados tipos - com seu corpo.

Uma vez que essas bases de funcionamento da sociedade espraiaram-se para quase todo o globo, é de suma importância para o conjunto dos educadores compreender como o capital não se descuidou de uma pedagogia do corpo. Essa pedagogia incluía as práticas corporais institucionalizadas e a disciplina curricular escolar Educação Física, mas não se esgotava nelas.

Com base nessas considerações, este texto buscará apreender elementos centrais acerca da educação do corpo no bojo do industrialismo, tendo como suporte a discussão de Antonio Gramsci. Ainda que Gramsci não tenha teorizado nos Cadernos do cárcere aspecto específico algum do campo da Educação Física, suas observações, sobretudo no caderno 22 (Americanismo e fordismo), trazem questões relevantes sobre o papel do corpo nessa nova fase de funcionamento do capitalismo. É possível reconhecer, por exemplo, que o americanismo/fordismo implica numa nova relação do trabalhador com seu trabalho e sua vida, em diversos âmbitos. Assim, será debatido como o nascente industrialismo precisou radicalizar o código moral asséptico - contando inclusive com forte auxílio da Igreja - numa constante busca por educar o consenso de homens e mulheres que viviam - e ainda vivem da venda de sua força de trabalho.

Este texto é composto por duas seções. A primeira irá debater a consolidação dos processos de urbanização e industrialização no bojo de uma nova correlação de forças no sistema capitalista internacional, em que lentamente os EUA tomam da Inglaterra o lugar de principal país capitalista. Na segunda seção, encontrar-se-á a discussão pautada no marxista italiano acerca da dimensão corporal do processo de sociabilidade demandado pelas modificações no âmbito do projeto capitalista, por Antonio Gramsci chamado de americanismo e fordismo.

Dessa maneira, o recorte nas contribuições de Gramsci pretende demonstrar sua possibilidade de lançar luz sobre aspectos negligencia- 
dos no debate acerca da história da educação do corpo na sociedade capitalista.

\section{Generalização da sociedade urbana industrial e o americanismo}

Mais do que modificações apenas nas unidades produtivas, o fordismo representou uma intensa ação do capital no conjunto da vida social nas sociedades capitalistas. Essa forma social não guarda sua especificidade na produção de mercadorias em série e, menos ainda, no fato de o avanço das forças produtivas via incorporação cada vez mais intensa de ciência e tecnologia ter desembocado, num primeiro momento, na substituição das velhas manufaturas pelas grandes indústrias. Sua especificidade deve ser buscada nas relações sociais travadas entre os seres humanos no momento de obterem sua existência, bem como nos mecanismos de extração do trabalho excedente. Estes deixam de contar com a coerção política para fazê-lo por meio econômico, mediante a forma de operar do dito mercado (WOOD, 2003).

A atuação estatal na organização da vida social na ordem burguesa passou a assumir níveis inéditos e crescentes a partir das décadas iniciais do século $\mathrm{XX}$, ainda que com consideráveis variações em função das correlações de forças em cada formação social concreta. Ainda assim, não há uma relação de exterioridade entre a atuação estatal e a reprodução das relações sociais capitalistas. Diante disso, Poulantzas (2000, p. 17-18) afirma:

A separação do Estado e do espaço de reprodução, específico do capitalismo, não deve ser tomada como efeito particular das instâncias essencialmente autônomas e compostas de elementos invariantes, qualquer que seja o modo de produção; porém, e sim, como características próprias ao capitalismo, na medida em que ele cria novos espaços do Estado e da economia, transformando seus próprios elementos. Esta separação não nos deve levar a crer em real exterioridade do Estado e da economia, como se o Estado só, do exterior, interviesse na economia. Esta separação é a forma precisa que encobre, sob o capitalismo, a presença constitutiva do político nas relações de produção e dessa maneira, em sua produção. 
A compreensão da especificidade da separação relativa entre o econômico e o político não está cancelada. Mesmo com o reconhecido "engajamento decisivo do Estado na economia", não se trata de uma "interpenetração crescente de dois domínios com limites intrínsecos" (POULANTZAS, 2000, p. 168).

Por isso, Poulantzas clama pela desconfiança de representações "topológicas" acerca da relação entre Estado e economia. Nunca tendo sido uma relação de exterioridade, a referida separação formal do político e do econômico nada mais é do que "a forma específica da presença, sob o capitalismo, do Estado nas relações de produção" (p. 168). Apenas com esse alerta metodológico é possível manter a expressão "intervenção estatal na economia", visto estar indicado um quê de exterioridade nessa relação, algo que efetivamente não se dá na realidade concreta. Isso poderia levar à busca da diferença entre o Estado liberal contemporâneo aos fundadores do marxismo e a forma atual do Estado capitalista no fato de o primeiro ter uma intervenção econômica periférica e na atualidade ser central em sua atuação (POULANTZAS, 2000).

Além de ser equivocada historicamente - por não resistir à realidade dos fatos - essa argumentação é politicamente estéril para a compreensão da especificidade da ordem burguesa. Isso é explicitado por Poulantzas (2000) quando ele afirma que justamente devido ao fato de uma série de aspectos - "qualificação da força de trabalho, urbanismo, transporte, saúde, meio ambiente, etc." (p. 169), que anteriormente ocupavam papel marginal na intervenção estatal na economia - estarem diretamente relacionados, na atualidade, à reprodução e à valorização do capital, é "que o papel do Estado nesses domínios ganha um novo sentido" (p. 169). Não se trata de mudanças exteriores que incidiriam sobre uma realidade por si imutável, mas, ao contrário, que devem ser "compreendidas em seu lugar específico no interior de uma reorganização de conjunto do Estado" (p. 169).

Um ponto central é a explicitação do papel educativo do Estado capitalista, sendo fundamental a remissão constante à ampliação do conceito de Estado realizada pelo marxista italiano, nas chamadas sociedades ocidentais e em processos de ocidentalização. Assim, o Estado educador é a modalidade necessária de atuação estatal na consecução da hegemonia dominante. Tanto que o autor, debatendo acerca da ampliação estatal, aponta que "na noção geral de Estado entram elementos que devem ser remetidos à noção de sociedade civil (neste 
sentido, seria possível dizer que Estado $=$ sociedade política + sociedade civil, isto é, hegemonia encouraçada de coerção)" (GRAMSCI, 2000, p. 244).

Com essa ampliação do conceito de Estado, Gramsci identifica alterações na lógica de dominação burguesa, a partir da busca constante do consenso dos dominados operada mediante a ação de uma série de aparelhos privados de hegemonia na condição de intelectuais orgânicos das classes dominantes atuando na sociedade civil. Ao mesmo tempo, afirma que a luta política por parte do movimento anticapitalista também deve atentar para os embates nessa nova dimensão do ser social, com a ação de aparelhos privados de hegemonia da classe trabalhadora. Isso se deve à indicação de que a sociedade civil pode se transformar em trincheira para a dominação burguesa, com a atuação de seus aparelhos privados de hegemonia buscando sedimentar e difundir concepções de mundo funcionais ao projeto histórico dessa classe.

Diante disso, reafirmando o caráter de classe desse Estado ampliado, Gramsci mostra como a fração dominante no âmbito do bloco no poder concebe a atuação estatal em seu projeto político. Isso implica na relação desse Estado com as outras frações do bloco no poder e com as classes dominadas. Seja atendendo seletivamente algumas demandas, seja atuando na repressão daqueles que não consentem, o aparelho de Estado

é certamente concebido como organismo próprio de um grupo, destinado a criar as condições favoráveis à expansão máxima de grupo, mas este desenvolvimento e esta expansão são concebidos e apresentados como a força motriz de uma expansão universal, de um desenvolvimento de todas as energias "nacionais", isto é, o grupo dominante é coordenado concretamente com os interesses gerais dos grupos subordinados e a vida estatal é concebida como uma contínua formação e superação de equilíbrio instável (no âmbito da lei) entre os interesses do grupo fundamental e dos grupos subordinados, equilíbrio em que os interesses do grupo dominante prevalecem, mas até um determinado ponto, ou seja, não até o estreito interesse econômico-corporativo (GRAMSCI, 2000, p. 41-42). 
Essa forma própria de operar do Estado, sob relações sociais capitalistas, está diretamente relacionada com o grau das relações entre as classes sociais, e mesmo no interior da fração dominante. Assim, segundo o autor dos Cadernos do cárcere, $\mathrm{o}$

fato da hegemonia pressupõe indubitavelmente que sejam levados em conta os interesses e as tendências dos grupos sobre os quais a hegemonia será exercida, que se forme um certo equilíbrio de compromisso, isto é, que o grupo dirigente faça sacrifícios de ordem econômico-corporativa; mas também é evidente que tais sacrifícios e tal compromisso não podem envolver o essencial, dado que, se a hegemonia é ético-política, não pode deixar de ser também econômica, não pode deixar de ter seu fundamento na função decisiva que o grupo dirigente exerce no núcleo decisivo da atividade econômica (GRAMSCI, 2001, p. $48)$.

Assim, cada Estado procura criar, difundir e manter formas específicas de sociabilidade conforme o projeto societário do bloco no poder, assumindo uma função claramente educativa. Esse projeto educativo tem por objetivo, então, “adequar a 'civilização' e a moralidade das mais amplas massas populares às necessidades do aparelho econômico de produção e, portanto, de elaborar também fisicamente tipos novos de humanidade" (GRAMSCI, 2001, p. 23). Com isso, "o Estado deve ser concebido como 'educador' na medida em que tende precisamente a criar um novo tipo ou nível de civilização" (p. 28).

Gramsci, ao analisar o que chama de americanismo e fordismo, afirma serem essas expressões das mudanças internas das relações sociais capitalistas, não somente na dinâmica de funcionamento do trabalho, mas também nos modos de ser. Segundo o autor italiano, tal processo exigiu o que ele chama de uma "adaptação psicofísica". Isso se expressa na organização escolar, na vida familiar, nas diversões e no próprio âmbito do trabalho. O marxista italiano mostra - e é preciso lembrar que o desenvolvimento capitalista e a unificação política na Itália foram tardios, se comparados a outras formações sociais europeias - que tal processo atingiu diversas esferas da vida social, inclusive numa busca de ordenar a vida sexual dos trabalhadores, com recomendações e indicações de comportamentos a serem adotados (GRAMSCI, 2001). 
A expressão "americanismo" destina-se ao reconhecimento por Gramsci da centralidade que os EUA passaram a obter já antes da primeira grande guerra. Hobsbawm (2006, p. 101) afirma que em "1913 os EUA já haviam se tornado a maior economia do mundo, produzindo mais de um terço de sua produção industrial - pouco abaixo do total combinado de Alemanha, Grã-Bretanha e França". Esse percentual avança, em 1929, para 42\% da produção industrial mundial, superando em 14\% o total das outras três grandes potências europeias (HOBSBAWM, 2006).

Gramsci afirma que o americanismo representou a passagem do velho individualismo econômico para a economia programada, sendo o fordismo o "ponto extremo do processo de sucessivas tentativas da indústria no sentido de superar a lei tendencial da queda da taxa de lucro" (2001, p. 242). Mesmo sendo a Europa o berço do capitalismo, o marxista sardo viu uma posição mais avançada no outro lado do Atlântico, justamente pela ausência de classes dominantes tradicionais parasitas, sorvedoras da mais-valia produzida. Para ele, "a velha e anacrônica estrutura social-demográfica europeia" seria incompatível com a "forma moderníssima de produção e de modo de trabalhar, como aquela oferecida pelo tipo americano mais aperfeiçoado, a indústria de Ford" (GRAMSCI, 2001, p. 242).

Gramsci (2001, p. 247) afirma que, dada a inexistência de "grandes tradições históricas e culturais, mas tampouco [...] sufocada por esta camada de chumbo", os EUA puderam desempenhar o papel de ponta do capitalismo. Com isso, teria sido mais fácil a racionalização do trabalho e da produção, tendo havido a hábil combinação

da força (destruição do sindicalismo operário de base territorial) com a persuasão (altos salários, diversos benefícios sociais, habilíssima propaganda ideológica e política) e conseguindo centrar toda a vida do país na produção (GRAMSCI, 2001, p. 247).

Não por acaso, na sequência o autor dos Cadernos do cárcere traz sua conhecida afirmação de que "a hegemonia nasce da fábrica e necessita apenas, para ser exercida, de uma quantidade mínima de intermediários profissionais da política e da ideologia" (GRAMSCI, 2001, p. 247). 
Conforme já exposto, o autor afirma que tal empreendimento demandou

elaborar um novo tipo humano, adequado ao novo tipo de trabalho e de processo produtivo: esta elaboração está agora na fase inicial e, por isso, (aparentemente) idílica. É ainda a fase de adaptação psicofísica à nova estrutura industrial, buscada através dos altos salários (GRAMSCI, 2001, p. 248).

Gramsci tinha clareza que essa nova vida na indústria para amplos setores da classe trabalhadora - mesmo para aqueles que desempenhariam funções de prepostos das classes dominantes no processo produtivo - demandava uma sociabilidade de novo tipo. Era preciso adaptar-se psicofisicamente "a determinadas condições de trabalho, de nutrição, de habitação, de costumes, etc., que não é algo inato, 'natural', mas exige ser adquirido, ao passo que as características urbanas são transferidas por herança ou absorvidas no decorrer da infância e da adolescência" (GRAMSCI, 2001, p. 251). Assim, era necessário um "contínuo e relevante gasto com o aprendizado dos novos urbanizados e traz consigo uma permanente modificação da composição sociopolítica da cidade" (p. 251).

A grande contradição exposta no caderno sobre americanismo e fordismo é a admiração/repulsa que o autor apresenta em relação a esse processo. Isso se deve às suas discordâncias da forma como os processos de industrialização se deram ao longo dos anos 1920 na URSS, tendo continuado durante seus anos de cárcere. É necessário lembrar que Gramsci morre em 1937, tendo tido diversas polêmicas com o bureau central do Partido Comunista Russo acerca de muitos elementos.

Uma das principais preocupações de Gramsci no cárcere foi compreender o fracasso dos processos revolucionários na Europa continental, bem como o desnudamento da lógica de dominação burguesa em seu tempo, certamente diferente do que enfrentaram os fundadores do marxismo. Isso demandava a compreensão da forma mais avançada de capitalismo que se praticava no momento. Por isso, não há nos Cadernos apenas críticas ao americanismo, mas um nítido chamado de atenção aos comunistas que não deveriam ignorar essas transformações, caso quisessem ter alguma interface como educadores políticos da classe trabalhadora, em disputa com os representantes burgueses e/ou social-democratas. 
Certamente não se trata de uma perspectiva de transferência da organização científica do trabalho do capitalismo ao socialismo, como bem ressalta Liguori (2000). Ainda que essa crença não tenha sido rara no movimento comunista da época, ou seja, de um uso socialista do taylorismo, na forma de um suposto americanismo comunista, e que mesmo Gramsci tenha seguido essa linha nos escritos do final dos anos 1910, não pode ser tributada uma abordagem ingênua dessa questão. Liguori (2000, p. 40) lembra com precisão que a fábrica que Gramsci tinha diante de si era, "em grandíssima medida, uma fábrica pré-fordista".

\section{Gramsci, americanismo e fordismo e educação do corpo}

Diversos estudos da área de Educação Física afirmam e demonstram como o projeto societário burguês, como parte do processo de consolidação do modo capitalista de produção social da existência, atribuiu, ao longo dos séculos XIX e XX, um papel central às práticas corporais (SOARES, 2000; VIGARELLO, 2003). São comuns na literatura da Educação Física menções aos esportes e demais práticas corporais como elementos centrais na formação da nova sociabilidade requerida pelo capital, tanto na Europa e nos Estados Unidos como nos países periféricos (SOARES, 2000; VIGARELLO, 2003).

Havia não apenas uma pedagogia das práticas corporais, visualizada nos diversos métodos de ginástica (sueco, francês, alemão), mas também toda uma organização nas relações sociais que orientavam uma nova conduta perante a sociedade (SOARES, 2000; VIGARELLO, 2003). Não por acaso, afirma Soares (2000, p. 46) que

é a partir deste reconhecimento que, de fato, a Ginástica passa a ser vista como prática capaz de potencializar a necessidade de utilidade das ações e dos gestos e de ensinar o indivíduo a internalizar uma noção de economia de tempo, de gasto de energia e de cultivo à saúde como princípios organizadores do cotidiano.

Ainda com essa autora temos que o corpo passa a ser tomado como um objeto cognoscível e mensurável, "como conjunto de forças capaz de pôr em movimento determinações precisas, conter e reprimir desejos, preservar energia" (SOARES, 2000, p. 46). Tal leitura indica sua vinculação orgânica e umbilical com essa nova lógica de funciona- 
mento da nascente sociedade capitalista. Que fique claro: tal processo não se limita à organização do trabalho em âmbito fabril, mas em todos os âmbitos da vida social.

Ao aprofundar esse debate, Vigarello (2003) afirma que a ginástica se relacionava com a indispensável demanda capitalista por precisão, rendimento, produtividade, melhora constante de resultados. Por conta disso, tais resultados deviam "ser vistos, aferidos entre si, figuráveis no rigor de uma tabela" (VIGARELLO, 2003, p. 13).

Os cuidados de si como elemento central para a saúde passaram a ganhar grande destaque. Não há motivos para discordar da necessidade que a ordem burguesa tinha de uma força de trabalho saudável, disciplinada, em condições de ser posta em funcionamento tão logo o capital demandasse. Cabe lembrar que os processos de configuração de um exército industrial de reserva implicam, sempre, na necessidade de força de trabalho em condições de "entrar em campo", tão logo seja convocada. Por conta disso, os cuidados de si não abarcam somente aqueles que estão vendendo a força de trabalho, mas também aqueles que, conjunturalmente, não o estão. Seja entre mulheres, crianças ou homens, os cuidados de si deveriam, na medida do possível e do necessário, ser universalizados pelo capital, para que não faltasse a mercadoria força de trabalho em condições e quantidade suficiente que pudesse implicar na alta de seu preço.

De certa forma, Gramsci analisa no caderno 22 processos de educação corporal no tocante à sociabilidade que atingem diversas esferas da vida social. A forja de um novo homem e de uma nova mulher em conformidade com o tempo de generalização da industrialização demandou intensos esforços de controle da sociabilidade dos trabalhadores por parte do conjunto da classe burguesa. Essa pedagogia corporal do capital exigia

uma luta contínua contra o elemento "animalidade" do homem, um processo ininterrupto, frequentemente doloroso e sangrento, de sujeição dos instintos (naturais, isto é, animalescos e primitivos) a normas e hábitos de ordem, de exatidão, de precisão sempre novos, mais complexos e rígidos, que tornam possíveis as formas cada vez mais complexas de vida coletiva, que são a consequência necessária do desenvolvimento do industrialismo (GRAMSCI, 2001, p. 262). 
Isso incide especificamente na relação dos trabalhadores e trabalhadoras com o corpo, o próprio e o do outro. O marxista italiano mostra que foram "os instintos sexuais os que sofreram maior repressão por parte da sociedade em desenvolvimento" (GRAMSCI, 2001, p. 249), até mesmo os que o autor chama de normais. Em função de "um desequilíbrio permanente na relação numérica entre os indivíduos dos dois sexos" (p. 264), a repressão sexual atingiu grande intensidade. Para Gramsci, os novos métodos de trabalhos racionalizados/taylorizados demandam uma intensa "disciplina dos instintos sexuais (do sistema nervoso), ou seja, um fortalecimento da 'família' em sentido amplo (não desta ou daquela forma do sistema familiar), da regulamentação e da estabilidade das relações sexuais" (p. 264).

O processo de complexificação das relações sociais capitalistas, bem como as novas configurações sociais decorrentes de tal processo, impulsionou a popularização dos esportes como forma de lazer, sobretudo, mas não exclusivamente, para a burguesia. Novas tecnologias de comunicação também colaboraram para a divulgação dessas novas práticas corporais.

Posteriormente, com a ascensão dos EUA a potência no cenário capitalista mundial, redundando em mudanças qualitativas no modus operandi das classes dominantes, os esportes ganharam novos impulsos. Por exemplo, sendo sistematizadas no interior dos aparelhos privados de hegemonia estadunidenses conhecidos como Associações Cristãs de Moços (ACMs) algumas manifestações esportivas como voleibol e basquetebol, na década de 1890 .

Hobsbawm (2008) destaca o papel dos esportes na produção da identificação nacional, principalmente a partir do período entre as duas guerras mundiais, a despeito da existência dos Jogos Olímpicos desde 1896. Esse papel dos esportes era traduzido, sobretudo, mediante sua transformação em espetáculo de massa, e por representar "uma sucessão infindável de contendas, onde se digladiavam pessoas e times simbolizando Estados-nações, o que hoje faz parte da vida global" (HOSBSBAWM, 2008, p. 170). No período anterior à Primeira Guerra Mundial, afirma o historiador inglês, os esportes em suas múltiplas expressões eram eventos que atraíam, especialmente, as frações mais escolarizadas da sociedade. As diversões dos trabalhadores em diversos países não eram majoritariamente esportivas. As competições esportivas internacionais ainda eram tomadas como competições entre pesso- 
as, como constantemente lembrava o Movimento Olímpico. Somente no entreguerras essas competições passaram a ser concebidas

com o objetivo de integrar os componentes nacionais dos Estados multinacionais. Eles simbolizavam a unidade desses Estados, assim como a rivalidade amistosa entre suas nações reforçava o sentimento de que todos pertenciam a uma unidade, pela institucionalização de disputas regulares, que proviam uma válvula de escape para as tensões grupais, as quais seriam dissipadas de modo seguro nas simbólicas pseudolutas (HOBSBAWM, 2008, p. 170-171).

Assim, por via dos atletas, os esportes passaram a se tornar expressões dos países em embates não bélicos entre si. Isso ocorreu não somente no futebol. Hobsbawm (2008) afirma que a famosa Volta da França de Ciclismo (Tour de France), disputada desde 1903, passou a ser considerada uma competição de times nacionais de ciclistas, inclusive no que tange à elaboração de táticas de equipes para que um dos seus vença, e não mais uma corrida individual. Como afirma o autor de A era dos extremos, $o$

que fez do esporte um meio único, em eficácia, para inculcar sentimentos nacionalistas, de todo modo só para homens, foi a facilidade com que até mesmo os menores indivíduos políticos ou públicos podiam se identificar como a nação, simbolizada por jovens que se destacavam no que praticamente todo homem quer, ou uma vez na vida terá querido: ser bom naquilo que faz. A imaginária comunidade de milhões parece mais real na forma de um time de onze pessoas com nome. O indivíduo, mesmo aquele que apenas torce, torna-se o próprio símbolo da nação (HOBSBAWM, 2008, p. 171).

Gramsci traz uma série de elementos tirados da implantação do fordismo nos EUA. Começa apontando como "a racionalização do trabalho e o proibicionismo ${ }^{1}$ estavam indubitavelmente ligados" (GRAMSCI, 2001, p. 266), bem como a existência de iniciativas dos empresários de investigar "a vida íntima dos operários, os serviços de inspeção criados por algumas empresas para controlar a 'moralidade' dos operários", sendo isso "necessidades do novo método de trabalho" 
(p. 266). Mais ainda, alerta ser um equívoco político ironizar essas iniciativas. Caso os comunistas tomassem tais processos

apenas [como] uma manifestação hipócrita de "puritanismo" estaria[m] se negando qualquer possibilidade de compreender a importância, o significado e o alcance objetivo do fenômeno americano, que é também o maior esforço coletivo até agora realizado para criar, com rapidez inaudita e com uma consciência do objetivo jamais vista na história, um tipo novo de trabalhador e de homem (GRAMSCI, 2001, p. 266).

O autor ressalta que sua expressão "consciência do objetivo" relata precisamente o sentido de tais medidas, que certamente incidem sobre o corpo do trabalhador de novo tipo. Comparando a expressão "gorila amestrado", empregada por Taylor para definir o perfil do novo trabalhador requerido por seu método de organização da produção, Gramsci (2001, p. 266) indica ser a expressão direta do

brutal cinismo [d]o objetivo da sociedade americana: desenvolver em seu grau máximo, no trabalhador, os comportamentos maquinais e automáticos, quebrar a velha conexão psicofísica do trabalho profissional qualificado, que exigia uma certa participação ativa da inteligência, da fantasia, da iniciativa do trabalhador, e reduzir as operações produtivas apenas ao aspecto físico maquinal ${ }^{2}$.

1-Gramsci estava analisando os desdobramentos da chamada política proibicionista nos EUA. De 1920 a 1933 esteve em vigor uma emenda à constituição estadunidense - conhecida como Lei Seca - que proibia a fabricação, o comércio, o transporte, a importação e a exportação de bebidas alcoólicas. Houve intenso comércio ilegal de álcool nesse momento.

2-O marxista sardo afirma que tal processo "não se trata de nenhuma novidade original" sendo apenas a "fase mais recente de um longo processo que começou com o próprio nascimento do industrialismo, uma fase que é apenas mais intensa do que as anteriores e se manifesta sob as formas mais brutais, mas que também será superada através da criação de um novo nexo psicofísico de um tipo diferente das anteriores e, certamente, de um tipo superior" (GRAMSCI, 2001, p. 266). 
Esse novo puritanismo, sobretudo no que tange ao álcool e à vivência da sexualidade, tem como alvos centrais os trabalhadores, ou seja, incide na separação que se formou e que Gramsci (2001, p. 268) dizia que se acentuaria mais ainda entre "a moralidade-costume dos trabalhadores e aquela de outras camadas da população". O autor mostra isso fazendo a pergunta sobre qual classe social consumia álcool no período do proibicionismo estadunidense, tendo esse produto se tornado "mercadoria de grande luxo e nem mesmo os altos salários podiam permitir que fossem consumidos pelos mais amplos estratos das massas trabalhadoras" (p. 268). Gramsci afirma que o trabalhador com jornada fixa, que trabalha por salário, não disporia de tempo para realizar uma ampla busca por álcool em condições (de preço) de ser consumido.

O marxista sardo afirma que a mesma lógica se aplica à sexualidade. Utilizando a linguagem metafórica e talvez machista - ainda que colocada entre aspas no original - ele, de forma muito irônica, afirma que

a "caça à mulher" exige bastante "ócio"; no operário de tipo novo se repetirá, sob outras formas, o que ocorre nas aldeias camponesas. A relativa solidez das uniões sexuais camponesas liga-se estritamente ao sistema de trabalho rural. O camponês que volta para casa à noite, depois de uma longa jornada de trabalho, deseja a Venerum facilem parabilemque de Horácio: não tem o hábito de correr atrás de prostitutas; ama sua mulher, segura, sempre presente, que não fará dengo nem pretenderá a comédia da sedução e do estupro para ser possuída. Aparentemente, isso faz com que a função sexual se torne mecânica; mas, na realidade, trata-se de uma nova forma de união sexual, sem as cores "fascinantes" da fantasia romântica própria do pequeno-burguês e do boêmio vadio. Revela-se claramente que o novo industrialismo quer a monogamia, quer que o homem-trabalhador não desperdice suas energias nervosas na busca desordenada e excitante da satisfação sexual ocasional: o operário que vai para o trabalho depois de uma noite de "orgias" não é um bom trabalhador; a exaltação passional não 
pode se adequar aos mais perfeitos automatismos (GRAMSCI, 2001, p. 268-269, grifo nosso) $)^{3}$.

Fica explícita a compreensão de Gramsci de ser o moralismo parte inerente do modus vivendi demandado pela sociedade burguesa de novo tipo. Que fique claro: esse moralismo é exigido, sobretudo do trabalhador e da trabalhadora, de modo radicalmente mais intenso sobre esta. Mais ainda, a brutalização e a mecanização das relações sexuais conjugais estariam relacionadas a essa dinâmica societal. A crueza da definição de Gramsci acerca do comportamento do marido e da mulher camponesa no momento de suas relações sexuais ("não fará dengo nem pretenderá a comédia da sedução e do estupro para ser possuída"), que de certa forma atingiria também o trabalhador da nova indústria, indica uma pedagogia da vivência da sexualidade em que a condição humana de fazer da relação sexual fonte de prazer, e não apenas de reprodução, torna-se uma grande barreira ao americanismo, devendo ser enfrentada. Por isso, os trabalhadores e trabalhadoras precisariam ter direito apenas a fugazes momentos de felicidade.

Os processos descritos no referido caderno 22 foram escritos por Gramsci em 1934, ou seja, no auge do seu amadurecimento intelectual no cárcere. A aproximação do esgotamento de suas forças, que o levaria à morte em 1937, fez que os Cadernos possuíssem um refinamento teórico que era fruto desse amadurecimento e da clareza do que representava a experiência italiana de Mussolini no contexto da nova ordem mundial -às portas da Segunda Grande Guerra, já com Hitler no poder, e no pós-crise de 1929, com a recuperação econômica estadunidense (COUTINHO, 2003).

3-Não é possível a defesa da presença de uma concepção machista no autor dos Cadernos do cárcere. Em sua relação com as mulheres da família, Gramsci defende peremptoriamente a importância de suas sobrinhas terem acesso aos níveis avançados de educação, sendo cobradas nos estudos tanto quanto os meninos. Além disso, há uma constante valorização das incursões de sua esposa Iulca (Julia) no mundo do trabalho, malgrado suas adversas condições de saúde. Não obstante, no caderno 22, o marxista sardo afirma ser indispensável a "formação de uma nova personalidade feminidade" (GRAMSCI, 2001, p. 251). Nesse processo o autor sugere cautela, em virtude da ocorrência de aspectos mórbidos na questão sexual, "enquanto a mulher não tiver alcançado não apenas uma real independência em face do homem, mas também um novo modo de conceber a si mesma e a seu papel nas relações sexuais" (p. 251).

Pensar a Prática, Goiânia, v. 15, n. 2, p. 272-550, abr./jun. 2012 


\title{
Seguindo o debate
}

As diversas intervenções na vida social, buscando conformar uma sociabilidade às novas necessidades do capital, tiveram frentes distintas. Esse processo teve certamente uma dimensão corporal. O debate, longe de refletir-se em qualquer fragmentação entre corpo e mente, busca indicar uma pedagogia social da ordem burguesa que procura abarcar o trabalhador em sua totalidade. A forja desses novos homens e mulheres teve certamente uma preocupação simbólica, sentimental e até racional. Contudo, a expressão concreta desse processo reverberava no corpo.

O desnudar da hipocrisia das ditas intervenções moralistas e puritanas é parte importante da luta pela emancipação política e econômica na busca da superação das relações sociais capitalistas. A clareza que o reino da necessidade, sob as bases capitalistas, lança sobre toda existência do ser social, leva-nos a vislumbrar que os momentos de liberdade muitas vezes se tornam prêmios de bom comportamento na ordem burguesa. Isso é expresso em parte nas diversões que a ordem burguesa sugere àqueles que necessitam retornar em condições psicofísicas para a extenuante, incerta e precária jornada de trabalho diária.

A crítica dessa concepção deve ser tomada como uma tarefa político-pedagógica daqueles que, malgrado os enormes desafios, têm claro que a ordem do capital só é passível de permanecer existindo com a intensificação cada vez maior da exploração do ser humano e da natureza. E isso já é mais do que suficiente para o engajamento numa luta anticapitalista nos mais diversos planos da vida social. Essa luta se dará em diversas frentes, inclusive no campo da ideias.

\section{Gramsci, americanism and fordism and body education}

\begin{abstract}
Antonio Gramsci theorized certainly not in the Prison Notebooks any particular aspect of physical education. Nevertheless, considerations, especially in the Book 22 (Americanism and Fordism) bring relevant issues to think about the role of the body in the change of type of capitalism that it came into Europe in the 1930s. Whereas these bases of operation of the company spread to almost all over the globe, is extremely important for all educators to understand how the capital did not neglect a pedagogy of the body, including, but not limited practice bodily discipline through sport and physical education curriculum.
\end{abstract}

Keywords: Gramsci. Americanism and Fordism. Body Education. Domination.

Pensar a Prática, Goiânia, v. 15, n. 2, p. 272-550, abr./jun. 2012 
Gramsci, el americanismo y el fordismo y la educación del cuerpo

\section{Resumen}

Antonio Gramsci teorizó no ciertamente en el Cuadernos de la cárcel cualquier aspecto particular de la educación física. Sin embargo, las consideraciones, especialmente en el libro 22 (americanismo y el fordismo) someter las cuestiones relativas a reflexionar sobre el papel del cuerpo en el cambio de tipo de capitalismo que entró en Europa en la década de 1930. Considerando que estas bases de operación de la empresa se extendió a casi todo el mundo, es muy importante para todos los educadores a comprender cómo el capital no se olvidó de una pedagogía del cuerpo, incluyendo, pero no la práctica limitada la disciplina del cuerpo a través del deporte y el currículo de educación física.

Palabras clave: Gramsci. Americanismo y el Fordismo. Educación del Cuerpo. Dominación.

\section{Referências}

COUTINHO, C. N. Gramsci: um estudo sobre seu pensamento político. 2. ed. Rio de Janeiro: Civilização Brasileira, 2003.

GRAMSCI, A. Cadernos do cárcere. v. 3. Maquiavel. Notas sobre o Estado e a política. Rio de Janeiro: Civilização Brasileira, 2000.

GRAMSCI, A. Cadernos do cárcere. v. 4. Temas de cultura. Ação católica. Americanismo e fordismo. Rio de Janeiro: Civilização Brasileira, 2001.

HOBSBAWM, E. A era dos extremos: o breve século XX: 19141991. 33. reimp. São Paulo: Companhia das Letras, 2006.

HOBSBAWM, E. Nações e nacionalismo desde 1780: programa, mito e realidade. 5. ed. São Paulo: Paz e Terra, 2008.

LIGUORI, G. O pensamento de Gramsci na época da mundialização. Educação em Foco, Juiz de Fora, v. 5, n. 2, p. 33-51, set. 2000.

POULANTZAS, N. O Estado, o poder, o socialismo. Rio de Janeiro: Graal, 2000.

SOARES, C. L. Notas sobre a educação no corpo. Educar, Curitiba, n. 16, p. 43-60, 2000. 
VIGARELLO, G. A invenção da ginástica no século XIX: movimentos novos, corpos novos. Rev. Bras. Cienc. Esporte, Campinas, v. 25, n. 1, p. 9-20, set. 2003.

WOOD, E. M. Democracia contra capitalismo: renovação do materialismo histórico. São Paulo: Boitempo, 2003.

Recebido em: 04/08/2010

Revisado em: 20/11/2010

Aprovado em: 03/02/2011

Endereço para correspondência

marcelaomelo@gmail.com

Marcelo Paula Melo

Instituto Superior de Educação- FAETEC.

Rua Marechal Deodoro, 117

Centro

24452-001 - Tres Rios, RJ - Brasil 